\title{
Review Article \\ Hypnosis in the Perioperative Management of Breast Cancer Surgery: Clinical Benefits and Potential Implications
}

\author{
Arnaud Potié, Fabienne Roelants, Audrey Pospiech, \\ Mona Momeni, and Christine Watremez \\ Cliniques Universitaires Saint-Luc, Université Catholique de Louvain, Service d'Anesthésiologie, \\ 10 Avenue Hippocrate, 1200 Brussels, Belgium \\ Correspondence should be addressed to Arnaud Potié; arnaudpotie@hotmail.com
}

Received 5 April 2016; Revised 27 July 2016; Accepted 28 July 2016

Academic Editor: Michael Frass

Copyright (C) 2016 Arnaud Potié et al. This is an open access article distributed under the Creative Commons Attribution License, which permits unrestricted use, distribution, and reproduction in any medium, provided the original work is properly cited.

\begin{abstract}
The aim of this review is to summarize data published on the use of perioperative hypnosis in patients undergoing breast cancer surgery (BCS). Indeed, the majority of BCS patients experience stress, anxiety, nausea, vomiting, and pain. Correct management of the perioperative period and surgical removal of the primary tumor are clearly essential but can affect patients on different levels and hence have a negative impact on oncological outcomes. This review examines the effect of clinical hypnosis performed during the perioperative period. Thanks to its specific properties and techniques allowing it to be used as complementary treatment preoperatively, hypnosis has an impact most notably on distress and postoperative pain. During surgery, hypnosis may be applied to limit immunosuppression, while, in the postoperative period, it can reduce pain, anxiety, and fatigue and improve wound healing. Moreover, hypnosis is inexpensive, an important consideration given current financial concerns in healthcare. Of course, large randomized prospective studies are now needed to confirm the observed advantages of hypnosis in the field of oncology.
\end{abstract}

\section{Introduction}

Breast cancer $(\mathrm{BC})$ is an important public health concern. It is the most commonly encountered cancer among women worldwide and the leading cause of cancer-related mortality [1]. To improve outcomes, breast cancer surgery (BCS) is often required but can negatively affect patients on different levels, triggering psychological, physical, metabolic, neuroendocrine, inflammatory, and immunological changes [26]. During the perioperative period, anesthesiologists attempt to maintain homeostasis and induce a sense of comfort to offset the "stress reaction" frequently suffered by patients (including psychological and physiological stress) [4, 5, 7-9]. Relationships between the psychological and physiological aspects of cancer have been investigated by psychoneuroimmunology. Studies have shown that prolonged psychological stress probably impairs the immune response, which is one of the fundamental factors in the prognosis of oncology patients [10]. Thanks to the bidirectional communication between the neuroendocrine and immune systems, activation of one stimulates the other, which could constitute an additional strategy for perioperative clinical management of cancer patients [10].

Surgery is commonly required in the treatment of cancerous tumors, but this period is often considered critical for oncological outcomes because of the risk of tumor dissemination and possible depressive effects on immunity. Despite the growing array of available adjuvant therapies, tumor recurrence (local and distant dissemination) still remains the leading cause of death due to cancer $[2,3]$.

The aim of this review is to evaluate the contribution hypnosis can make during the perioperative period of BCS. A multimodal approach will be presented, as hypnosis can impact clinical, psychological, and pathophysiological aspects, which may all be involved in the outcome of cancer patients.

\section{A Brief History of Hypnosis in Breast Cancer Management}

Use of hypnosis in the treatment of BC started with a French surgeon, Cloquet, back in 1829 [11, 12]. This was the first 
documented application of hypnosis in BCS. Cloquet performed a mastectomy with axillary dissection, while the patient's physician, Dr. Chapelin, practiced something known as "magnetic sleep," the word "hypnosis" not yet existing at that time [13].

After 1847, much major surgery, including breast surgery, was performed under hypnosis, but once ether and chloroform were made available to medical teams, these drugs became the standard of care for clinical anesthesia $[14,15]$. Thus, hypnosis gradually disappeared from the "anesthetic environment." Nevertheless, cases of BCS with hypnosis have been reported throughout the history of hypnosis [16].

During the 1950s, hypnosis was used as adjuvant therapy in the management of BC. In some cases, it was performed to reduce pain related to metastatic BC [17]. In the 1960s, Cangello showed the positive effect and power of posthypnotic suggestions to alleviate pain in cancer patients [18].

In 1983, Spiegel published the results of the first randomized controlled trial on the contribution of hypnosis to reducing pain in case of metastatic BC [19]. Since then, interest in hypnosis, initially focused on pain, has broadened to a general oncology treatment context.

Since 1992, hypnosis has been seen in operating rooms for procedures such as thyroidectomy, parathyroidectomy, and plastic surgery [20]. It can currently be used instead of general anesthesia for tumorectomies, quadrantectomies, and even mastectomies, in association with local or regional anesthesia $[21,22]$.

\section{What Is Hypnosis? From Neurological Concepts to the Operating Room}

It is difficult to provide a clear, uniform, and precise definition of hypnosis, as it depends upon the theoretical framework embraced by a given practitioner. However, the definition proposed by Montgomery characterizes hypnosis as "an agreement between a person designated as the hypnotist (e.g., healthcare professional) and a person designated as the client or the patient to participate in a psychotherapeutic technique based on the hypnotist providing suggestions for changes in sensation, perception, cognition, affect, mood, or behavior" [23]. This definition places emphasis on the relationship between hypnotist and patient, a necessary condition for anyone practicing hypnosis. More recently, the American Psychological Association (Division 30) proposed a definition of hypnosis as "a state of consciousness involving focused attention and reduced peripheral awareness characterized by an enhanced capacity for response to suggestion" [24].

From a clinical point of view, there are three basic phases during a hypnosis session, starting with induction, followed by therapeutic suggestions and concluded by emergence from the hypnotic state. During the induction phase, the therapist helps the patient to relax, imagine a peaceful scene, and become more focused on a "daydream." During the second phase, the therapist provides the patient with suggestions. These suggestions are the key ingredients of hypnosis intended to treat specific symptoms or difficulties. For example, if the patient is prone to anxiety, the therapist may suggest that, during and/or following hypnosis, he/she will feel calmer or less bothered by those feelings. Emergence from hypnosis involves helping the patient recover a normal state of consciousness. The main and crucial element that distinguishes hypnosis from meditation or a relaxation session is use of suggestion [25].

When asked about their experience, patients describe alterations in body image, time distortion, dissociation, feelings of relaxation and peace, attentional focus, and increased positive affectivity, but diminished self-awareness and memory [26].

From a neurocognitive and neuroscientific perspective, hypnosis was thought to be mediated by the right cerebral hemisphere. This theory was supported by the discovery of hemispheric specialization in the 1970s, and the brain was artificially divided into the creative right and analytic left [27]. This simplistic standpoint has since been replaced by a more global approach that recognizes the complexity of the hypnotic experience, which involves the frontal lobes, prefrontal cortex, and anterior cingulate cortex of both hemispheres. Moreover, current interest in hypnosis by the neuroscientific community has two main angles. First, it contributes to a better understanding of the neurocognitive nature of hypnosis and hypnotic phenomena (e.g., by studying the neural activities accompanying hypnosis induction) [28]. Second, it allows use of hypnosis as a "research tool" to investigate normal psychological processes and neural substrates of a phenomenon (e.g., pain perception, color vision) [27-29].

From a neuroanatomical point of view, studies using voxel-based morphometry are able to assess hypnotic suggestibility-linked and hypnosis depth-related differences in local gray matter volume, especially in parts of the frontal, temporal, and occipital cortex [30].

During hypnosis, activation of regional cerebral blood flow distribution is different from activation triggered by evoking episodic memory [31] and by the resting state [32]. Different parts of the brain are involved, including occipital, parietal, precentral, premotor, and ventrolateral prefrontal areas, the anterior cingulate cortex, the thalamus, and the pontomesencephalic brainstem. Compared to "normal alertness" with mental imagery, a hypnotic state shows prominently decreased activity in the medial parietal cortex, particularly in the precuneus [31-33]. Precise data on neurophysiological findings are too specific to present here but have been well summarized by Vanhaudenhuyse et al. in a comprehensive review article [34].

While the neurobiological substrates of hypnosis have not been elucidated, results indicate that the attentional skills involved in hypnotizability may correlate with central dopaminergic activity [35].

Patients participate actively in the hypnotic experience through hypnotic techniques and suggestions; the hypnotic response is not effortless [36]. Hypnotic suggestions involve changes in the perception of elements and their cerebral interpretation, correlated with concomitant changes in neuroimages [37, 38].

During hypnosis, suggestions of analgesia lead to a higher pain threshold and/or decrease in pain perception. This effect has been demonstrated in a number of clinical trials and 
experimental pain studies on volunteers [34, 39]. This hypnoanalgesic effect appears to involve several pain pathways, such as the nociceptive reflexes, pain-related autonomic activity, and the supraspinal pain control system $[34,39,40]$. However, many factors can influence patient response to pain, including personality, cultural background, previous experiences, socioeconomic status, and psychosocial support.

Studies conducted by Faymonville et al. showed a significant reduction in pain scores, analgesic consumption, and postoperative nausea when patients underwent surgery with local anesthesia and hypnosis (hypnosedation) compared to general anesthesia $[20,40]$. Similarly, in a prospective randomized study, Defechereux et al. found lower pain levels, less fatigue, improved recovery rates, and a decreased inflammatory response (IL-6) one day after surgery with use of hypnoanalgesia compared to general anesthesia [41]. Hypnosis techniques enhance intraoperative comfort and reduce anxiety, pain, and intraoperative requirements for anxiolytic and analgesic drugs, while ensuring optimal surgical conditions and faster recovery rates $[22,42]$. In a prospective randomized trial, Lang et al. showed hypnosis to be beneficial during invasive medical procedures by decreasing pain and anxiety symptoms, improving hemodynamic stability, and shortening operating times [43].

To induce a hypnotic state during surgery, the therapistpatient relationship is crucial. Use of nonauthoritarian techniques promotes responsiveness to the therapist's suggestions, in addition to the patient's own responsiveness, driven by his/her desires and cooperation. Indeed, while mutual confidence is essential, the motivation and expectations of the patient are just as important as the specific means used to achieve the goals of this adjuvant therapy [40]. Moreover, at any time, the patient is free to change techniques (general anesthesia versus hypnosis), which intensifies the experience of self-mastery and self-control. It is the combination of all these elements that accounts for the increasing success of this psychological support during surgery. If confidence, motivation, and then cooperation are present, everybody can reach the hypnotic state.

\section{Contribution of Hypnosis during the Three Phases of Surgery}

4.1. Hypnosis during the Preoperative Period. Being diagnosed with cancer is a highly stressful experience for patients. BCS can be a particular source of anxiety and depression, as it impacts physical appearance, sexual identity, and life expectancy [44-46]. Other stress factors include specific fears; patients are often fearful of general anesthesia, anticipated pain, not waking up after surgery, and experiencing general postoperative discomfort, especially female patients [47].

In case of elective surgery, patients have time to prepare themselves. However, as the day of surgery approaches, they can experience higher anxiety and negative cognitions [48]. This causes emotional distress that may have a negative influence on postsurgery outcomes $[44,45,48]$. Individual distress variables, such as anxiety and catastrophizing thoughts, have been shown to be predictive of increased postoperative pain and chronic pain intensity [44, 49-51]. On the other hand, clinical studies reveal that preoperative psychological robustness (positive affectivity, dispositional optimism) predicts acute postoperative pain [52] and is an independent predictor of (and protector against) chronic postsurgical pain, even up to 4 months after surgery in a multivariate analysis [53].

The role of hypnosis in reducing distress related to medical procedures has been widely documented in the literature [54]. Schnur et al. showed a 15-minute presurgical hypnosis session to be an effective way of controlling preoperative distress in women awaiting diagnostic BCS, compared to a 15-minute presurgical attention control session [55]. Patients in the hypnosis group exhibited lower scores for preoperative emotional upset, depressed mood and anxiety, and better values on the visual analog scale of relaxation, than did attention controls. Montgomery's prospective randomized controlled trail illustrated the same perioperative benefits of a short presurgical hypnotic intervention [56]. Hypnosis was also found to mitigate self-reported postoperative pain (intensity and unpleasantness), discomfort, and emotional upset. Lang et al. showed that an adjuvant self-hypnosis relaxation session before the procedure decreased anxiety and pain levels during breast biopsy [57]. Moreover, preoperative hypnosis may yield positive postoperative effects, as demonstrated in a randomized study by Enqvist et al. [58]. They reported that preparation by self-hypnosis using recording tapes reduced postoperative nausea, vomiting, and analgesic requirements.

\subsection{Hypnosis during Surgery}

4.2.1. Background and Immunity Considerations. Surgical removal of the primary tumor is the main treatment option for most cancers, but the perioperative period is a critical time for cancer evolution $[3,7,59,60]$. Indeed, both surgical and medical factors play a role.

Surgical factors identified in human studies are related to tumor manipulation and tissue attrition, increasing shedding of malignant cells into the circulation, potentiating invasion of free malignant cells (mediated by matrix metalloproteinases and adhesion molecules), favoring a proangiogenic switch in micrometastases (VEGF), and increasing levels of growth factors (EGF) caused by tissue damage, and this encouraging local and distant recurrence $[59,60]$.

Medical factors are both endogenous and exogenous. Endogenous factors involve neuroendocrine (hypothalamicpituitary-adrenal axis) and nervous system (nociceptive pathways and sympathetic system) loops [59]. Both perioperative psychological stress [60] and tissue injury [5] trigger numerous metabolic and hormonal changes, resulting in a "stress response" involving sympathetic, endocrine, and immunological effects. This response is characterized especially by increased secretion of catecholamine and pituitary hormones [5]. Stress hormones, specifically catecholamines, opioids, and glucocorticoids, were shown in animal models to causally promote metastatic progression (immunological and nonimmunological mechanisms) [60]. Moreover, during the perioperative period, natural killer (NK) cells, a component 
of the immune system, are particularly vulnerable, and the decline in their cytotoxic activity potentially exposes patients to increased oncological risk $[59,61]$. In rats, stress caused by release of catecholamines was found to impair NK cell activity [62] and could therefore influence tumor progression [63].

Among exogenous factors, anesthesia and analgesic medications (e.g., opioids, nonsteroidal anti-inflammatory drugs (NSAIDs)) act directly and indirectly on immune cells [3, $59,60,64]$ and can potentially impact cancer recurrence or metastasis $[3,65,66]$. Morphine and its derivatives appear to depress NK cell activity in animal and human studies [59], while NSAIDs were shown to decrease the risk of BC in a retrospective human analysis [67]. Melamed et al. found that all anesthetics except propofol significantly reduced NK cell activity and increased lung tumor retention and lung metastasis in rats [64].

All these factors may well play a simultaneous role during the vulnerable period surrounding surgery, potentially affecting oncological outcomes. Control of these factors represents a window of opportunity to optimally manage cancer patients undergoing surgery. Maintaining their immune competence may therefore favor long-term remission [68].

\subsubsection{Do Hypnosis and Its Techniques Limit Immunosuppression?}

(a) Local and Locoregional Anesthesia. Locoregional anesthesia during surgery also appears to have potential benefits in preventing cancer recurrence [69-71]. In experimental studies, a decline was observed in the spread of tumor cells and tumor recurrence in rats receiving regional anesthesia together with general anesthesia, compared to rats receiving general anesthesia alone [72]. Exadaktylos et al. retrospectively studied 129 patients who underwent a mastectomy with axillary dissection for BC. Recurrence-free and metastasisfree survival were significantly better in the group given a paravertebral block compared to those given only general anesthesia [73].

Furthermore, in experimental in vitro studies, local anesthetics appear to have specific cytotoxic effects on the tumor itself, which could negatively affect tumor progression [74-76]. Jose et al. [76] showed that levobupivacaine has specific cytotoxic effect on cancer cells viability inhibiting mitochondrial energy production.

(b) Specific Effects of Hypnosis on Immunity. Hypnosis practiced during surgery serves to comfort patients and reduce stress. It avoids the need for general anesthesia, with all its common side effects, and may therefore mitigate any possible immunosuppressive effects of general anesthesia.

Moreover, modest but reliable evidence suggests that psychological intervention can modulate the immune system [77]. During periods of stress, hypnosis can influence the dysregulation of immune cells (cellular and humoral immunity) [78-80]. This modification of the immune system is proportional to the level of decreased stress (CD3+ and CD4+ T lymphocytes) [81].
In the field of $\mathrm{BC}$ oncology, hypnosis as adjuvant treatment increases the number of NK cells and CD8+ T cells [82]. In a randomized controlled trial, Eremin et al. found significant differences in immunological modulation (activated $\mathrm{T}$ cells, lymphokine-activated killer cells, and mature T cells) in patients who underwent relaxation training and guided imagery techniques [83]. Indeed, higher numbers of cytotoxic $\mathrm{T}$ cells have been associated with longer survival durations in women with metastatic BC [84].

Spiegel et al. published two randomized prospective studies on the benefits of psychosocial therapy with hypnosis and survival of patients with metastatic BC. In the first study [85], patients in the treatment group (weekly supportive group therapy with self-hypnosis) lived significantly longer (about 18 months) than patients in the control group (routine oncological care). In the second study [86], they showed that overall survival did not differ between groups unless a specific factor was included, namely, the presence $(+)$ or not $(-)$ of the estrogen receptor $(\mathrm{R})$ on the tumor. Patients who were $\mathrm{R}(-)$ had their survival expectations significantly improved by psychosocial treatment (educational materials and supportive group therapy training in learning selfhypnosis versus educational materials only), whereas no survival improvement was observed among $\mathrm{R}(+)$ patients.

(c) Suggestions and Possible Implications. During surgery, the anesthetist-hypnotherapist offers "suggestions," with instantly favorable effects that may persist over time [87]. At the end of surgery, posthypnotic suggestions ensure continued comfort $[43,88]$, including positive emotions and antistress strategies, serving to enhance management in the postoperative period. These suggestions are very powerful and can act for prolonged periods of time. Such biobehavioral factors can significantly influence underlying cellular and molecular processes of malignant cells [89, 90] and may possibly impact oncologic outcomes.

\subsubsection{Concluding Remarks on the Perioperative Period. In} summary, hypnosis eliminates the adverse effects of anesthetic drugs by avoiding their use, while potentiating the specific positive effects of hypnosis on immunity. Techniques that prevent stress limit the increase in catecholamine secretions and reduce the need for anesthetics and opioids and could therefore prove useful in decreasing the incidence of metastases. Hypnosis and its techniques can diminish the general stress response of the body, while having a positive impact on immunity, so, by combining local (or locoregional) anesthesia and hypnosis, we may limit perioperative immunosuppression and possibly influence the evolution of the disease. Prospective studies still need to be conducted, however, to confirm this speculation and demonstrate the real impact of perioperative hypnosis on immunity, and hence on survival, in BC patients.

4.3. Hypnosis during the Postoperative Period. The main adverse effects of postoperative surgical management of BC are nausea, vomiting, pain, and fatigue, and all of them can be mitigated by use of hypnosis and local anesthesia. 
During the hypnotic state, "suggestions" involving analgesic strategies can help to reduce pain [88]. In turn, nociceptive and analgesic control may have an impact on cancer evolution. Poor management of pain in the postoperative period has been shown to have numerous consequences on potential long-term recurrence of metastases in rats [91].

Another long-term consequence of poor management of acute postoperative pain is the risk of it becoming chronic [92]. It has been shown that the only independent variable predicting severe pain two days after surgery is preoperative anxiety [50]. Patients with high levels of anxiety are at greater risk of acute postoperative pain and increased opioid consumption [44], and we know that $41 \%$ of patients exhibit signs of intense stress during the preoperative anesthesia evaluation. However, the intraoperative use of hypnosis can cut opioid consumption after surgery [22]. Practicing hypnosis means being vigilant to patient needs and communicating appropriately, especially during postoperative visits, where opioid consumption can be further reduced by using painfree vocabulary [93].

Hypnosis can also have beneficial effects on postoperative wound healing. In a small randomized clinical trial, Ginandes et al. demonstrated the positive effects of hypnosis after mammoplasty [94]. Wound healing at both 1 and 7 weeks postsurgery was significantly improved in the hypnosis group.

A recent observational nonrandomized study compared groups of patients with the same characteristics but operated on either under hypnosis or general anesthesia. The number of postmastectomy lymphocele punctures was lower in the hypnosis group, as was the quantity of lymph fluid removed. Patients in the hypnosis group also showed a reduced incidence of asthenia induced by chemotherapy and radiotherapy and a lower rate of severe radiodermatitis. Finally, adherence to endocrine therapy was improved in the hypnosis group, while the incidences of hot flashes, joint or muscle pain, and asthenia were all significantly decreased [95]. Last but not least, using hypnosis for BCS has been shown to significantly shorten the hospital stay $[22,95]$.

\section{Hypnosis and Cost Savings}

Hypnosis is inexpensive, an important concern considering the current financial climate in hospitals and healthcare. Cost studies show a positive impact of using hypnosis in hospitals [20,96-98] and for BC in particular [12, 56, 57, 99]. Block [99] reported the economic benefits of using hypnosis in patients undergoing breast biopsy. Their findings were then further extrapolated by Montgomery $[12,56]$. It is important to note that surgery under hypnosis does not take longer than surgery under general anesthesia $[41,56,57]$. This is a key consideration given the high cost of occupancy of an operating room. As already stated, use of intraoperative hypnosis significantly shortens postoperative hospitalization [22,95], yielding considerable saving. Moreover, when surgery is performed with a simple hypnoanalgesic technique, postanesthetic care is not even required. Hypnosis therefore reduces postanesthesia recovery times too [38].

\section{Conclusions}

Use of hypnosis in the context of $\mathrm{BC}$ is not new and many of its advantages have already been described in a meta-analysis on hypnosis in a surgical setting [100]. Suggestions made during hypnosis may affect patient outcomes improving various aspects like negative affectivity, emotional distress, pain, and analgesic medication consumption, as well as physiological indicators, such as nausea, vomiting, asthenia, lymphocele, and treatment, and recovery times. According to another review, the benefits of hypnosis are greater in the preoperative period [101]. Future research therefore investigate whether use of hypnosis during surgery can have any long-term benefits too. Anesthesiologists, in their role as perioperative physicians, should have knowledge of hypnosis and the power of suggestion to enhance the general clinical outlook during BCS. Indeed, it is important that anesthesiologists bear in mind the potential long-term impact of these techniques on the prognosis of patients.

Hypnosis can be used at every step of recovery. Moreover, during the perioperative period, it offers a unique patientcentered approach, creating a special bond between the patient and anesthesiologist. The latter affirms his/her role as a perioperative physician, endorsing the value of our work in the management of patients admitted for surgery.

\section{Competing Interests}

The authors declare that they have no competing interests regarding the publication of this paper.

\section{References}

[1] A. Jemal, F. Bray, M. M. Center, J. Ferlay, E. Ward, and D. Forman, "Global cancer statistics," CA-A Cancer Journal for Clinicians, vol. 61, no. 2, pp. 69-90, 2011.

[2] Y. Goldfarb and S. Ben-Eliyahu, "Surgery as a risk factor for breast cancer recurrence and metastasis: mediating mechanisms and clinical prophylactic approaches," Breast Disease, vol. 26, no. 1, pp. 99-114, 2006.

[3] A. Gottschalk, S. Sharma, J. Ford, M. E. Durieux, and M. Tiouririne, "The role of the perioperative period in recurrence after cancer surgery," Anesthesia and Analgesia, vol. 110, no. 6, pp. 1636-1643, 2010.

[4] H. Kehlet, "Multimodal approach to control postoperative pathophysiology and rehabilitation," British Journal of Anaesthesia, vol. 78, no. 5, pp. 606-617, 1997.

[5] J. P. Desborough, "The stress response to trauma and surgery," British Journal of Anaesthesia, vol. 85, no. 1, pp. 109-117, 2000.

[6] A. Boker, L. Brownell, and N. Donen, "The Amsterdam preoperative anxiety and information scale provides a simple and reliable measure of preoperative anxiety," Canadian Journal of Anesthesia, vol. 49, no. 8, pp. 792-798, 2002.

[7] D. I. Sessler, "Long-term consequences of anesthetic management," Anesthesiology, vol. 111, no. 1, pp. 1-4, 2009.

[8] P. Forget, O. Simonet, and M. De Kock, "Cancer surgery induces inflammation, immunosuppression and neo-angiogenesis, but is it influenced by analgesics?" F1000Research, vol. 2, article 102, 2013. 
[9] M. De Kock, "Expanding our horizons: transition of acute postoperative pain to persistent pain and establishment of chronic postsurgical pain services," Anesthesiology, vol. 111, no. 3, pp. 461-463, 2009.

[10] E. M. V. Reiche, S. O. V. Nunes, and H. K. Morimoto, "Stress, depression, the immune system, and cancer," The Lancet Oncology, vol. 5, no. 10, pp. 617-625, 2004.

[11] J. Cloquet, "Ablation d'un cancer du sein pendant un sommeil magnétique," in Archives Générales de Médecine, lère Série 20, pp. 132-133, Paris Béchet, 1829.

[12] G. H. Montgomery, J. B. Schnur, and K. Kravits, "Hypnosis for cancer care: over 200 years young," CA: A Cancer Journal for Clinicians, vol. 63, no. 1, pp. 31-44, 2013.

[13] J. D. Riskin and F. H. Frankel, "A history of medical hypnosis," Psychiatric Clinics of North America, vol. 17, no. 3, pp. 601-609, 1994.

[14] A. H. K. Wobst, "Hypnosis and surgery: past, present, and future," Anesthesia and Analgesia, vol. 104, no. 5, pp. 1199-1208, 2007.

[15] J. Esdaile, Mesmerism in India, and Its Practical Application in Surgery and Medicine, Arno Press, New York, NY, USA, 1976, Reprint of 1846 edition Published by Longman, London, UK.

[16] B. Hollander, "Hypnosis and anæsthesia," Proceedings of the Royal Society of Medicine, vol. 25, no. 5, pp. 597-610, 1932.

[17] B. Butler, "The use of hypnosis in the care of the cancer patient," Cancer, vol. 7, no. 1, pp. 1-14, 1954.

[18] V. W. Cangello, "Hypnosis for the patient with cancer," The American Journal of Clinical Hypnosis, vol. 4, pp. 215-226, 1962.

[19] D. Spiegel and J. R. Bloom, "Group therapy and hypnosis reduce metastatic breast carcinoma pain," Psychosomatic Medicine, vol. 45, no. 4, pp. 333-339, 1983.

[20] M. E. Faymonville, J. Fissette, P. H. Mambourg, L. Roediger, J. Joris, and M. Lamy, "Hypnosis as adjunct therapy in conscious sedation for plastic surgery," Regional Anesthesia, vol. 20, no. 2, pp. 145-151, 1995.

[21] A. Bouzinac, A. Delbos, M. Mazières, O. Rontes, and J.-L. Manenc, "Hypnosis and ultrasound-guided paravertebral block in breast cancer surgery," Annales Francaises d'Anesthesie et de Reanimation, vol. 31, no. 7-8, pp. 644-645, 2012.

[22] F. Roelants, P. Georges, F. Ponchon, M. Berlière, and C. Watremez, "Breast cancer surgery under hypnosis and local anesthesia: feasibility and potential benefits: 8AP5-8," European Journal of Anaesthesiology, vol. 28, supplement 48, p. 122, 2011.

[23] G. H. Montgomery and J. Schnur, "Panel discussion on definition of hypnosis," in Proceedings of the Annual Meeting of the Society of Clinical and Experimental Hypnosis, Anaheim, Calif, USA, October 2007.

[24] G. R. Elkins, A. F. Barabasz, J. R. Council, and D. Spiegel, "Advancing research and practice: the revised APA division 30 definition of hypnosis," International Journal of Clinical and Experimental Hypnosis, vol. 63, no. 1, pp. 1-9, 2015.

[25] K. Kathy, "Hypnosis: adjunct therapy for cancer pain management," Journal of the Advanced Practitioner in Oncology, vol. 4, no. 2, pp. 82-88, 2013.

[26] E. Cardeña, P. Jönsson, D. B. Terhune, and D. MarcussonClavertz, "The neurophenomenology of neutral hypnosis," Cortex, vol. 49, no. 2, pp. 375-385, 2013.

[27] J. F. Kihlstrom, "Neuro-hypnotism: prospects for hypnosis and neuroscience," Cortex, vol. 49, no. 2, pp. 365-374, 2013.

[28] P. W. Halligan and D. A. Oakley, "Hypnosis and cognitive neuroscience: bridging the gap," Cortex, vol. 49, no. 2, pp. 359364, 2013.
[29] D. A. Oakley and P. W. Halligan, "Hypnotic suggestion: opportunities for cognitive neuroscience," Nature Reviews Neuroscience, vol. 14, no. 8, pp. 565-576, 2013.

[30] W. J. McGeown, G. Mazzoni, M. Vannucci, and A. Venneri, "Structural and functional correlates of hypnotic depth and suggestibility," Psychiatry Research: Neuroimaging, vol. 231, no. 2, pp. 151-159, 2015.

[31] M. E. Faymonville, M. Boly, and S. Laureys, "Functional neuroanatomy of the hypnotic state," Journal of Physiology-Paris, vol. 99, no. 4-6, pp. 463-469, 2006.

[32] P. Rainville, R. K. Hofbauer, T. Paus, G. H. Duncan, M. C. Bushnell, and D. D. Price, "Cerebral mechanisms of hypnotic induction and suggestion," Journal of Cognitive Neuroscience, vol. 11, no. 1, pp. 110-125, 1999.

[33] P. Rainville, R. K. Hofbauer, M. C. Bushnell, G. H. Duncan, and D. D. Price, "Hypnosis modulates activity in brain structures involved in the regulation of consciousness," Journal of Cognitive Neuroscience, vol. 14, no. 6, pp. 887-901, 2002.

[34] A. Vanhaudenhuyse, S. Laureys, and M.-E. Faymonville, "Neurophysiology of hypnosis," Neurophysiologie Clinique, vol. 44, no. 4, pp. 343-353, 2014.

[35] P. Lichtenberg, R. Bachner-Melman, R. P. Ebstein, and H. J. Crawford, "Hypnotic susceptibility: multidimensional relationships with Cloninger's tridimensional personality questionnaire, COMT polymorphisms, absorption, and attentional characteristics," International Journal of Clinical and Experimental Hypnosis, vol. 52, no. 1, pp. 47-72, 2004.

[36] M. Wyzenbeek and R. A. Bryant, "The cognitive demands of hypnotic response," International Journal of Clinical and Experimental Hypnosis, vol. 60, no. 1, pp. 67-80, 2012.

[37] S. M. Kosslyn, W. L. Thompson, M. F. Costantini-Ferrando, N. M. Alpert, and D. Spiegel, "Hypnotic visual illusion alters color processing in the brain," American Journal of Psychiatry, vol. 157, no. 8, pp. 1279-1284, 2000.

[38] S. W. G. Derbyshire, M. G. Whalley, V. A. Stenger, and D. A. Oakley, "Cerebral activation during hypnotically induced and imagined pain," NeuroImage, vol. 23, no. 1, pp. 392-401, 2004.

[39] A. Vanhaudenhuyse, M. Boly, S. Laureys, and M.-E. Faymonville, "Neurophysiological correlates of hypnotic analgesia," Contemporary Hypnosis, vol. 26, no. 1, pp. 15-23, 2009.

[40] M. E. Faymonville, P. H. Mambourg, J. Joris et al., "Psychological approaches during conscious sedation. Hypnosis versus stress reducing strategies: A Prospective Randomized Study," Pain, vol. 73, no. 3, pp. 361-367, 1997.

[41] T. Defechereux, C. Degauque, I. Fumal et al., "Hypnosedation: a new anesthesia technique for cervical endocrine surgery. A prospective randomized study," Annales de Chirurgie, vol. 125, no. 6, pp. 539-546, 2000.

[42] M.-E. Faymonville, T. Defechereux, J. Joris, J. P. Adant, E. Hamoir, and M. Meurisse, "Hypnosis, its daily clinical application in surgical settings," Revue Medicale de Liege, vol. 53, no. 7, pp. 414-418, 1998.

[43] E. V. Lang, E. G. Benotsch, L. J. Fick et al., "Adjunctive nonpharmacological analgesia for invasive medical procedures: a randomised trial," The Lancet, vol. 355, no. 9214, pp. 1486-1490, 2000.

[44] G. Özalp, R. Sarioglu, G. Tuncel, K. Aslan, and N. Kadiogullari, "Preoperative emotional states in patients with breast cancer and postoperative pain," Acta Anaesthesiologica Scandinavica, vol. 47, no. 1, pp. 26-29, 2003. 
[45] G. H. Montgomery and D. H. Bovbjerg, "Presurgery distress and specific response expectancies predict postsurgery outcomes in surgery patients confronting breast cancer," Health Psychology, vol. 23, no. 4, pp. 381-387, 2004.

[46] J. B. Schnur, G. H. Montgomery, M. N. Hallquist et al., "Anticipatory psychological distress in women scheduled for diagnostic and curative breast cancer surgery," International Journal of Behavioral Medicine, vol. 15, no. 1, pp. 21-28, 2008.

[47] P. Mavridou, V. Dimitriou, A. Manataki, E. Arnaoutoglou, and G. Papadopoulos, "Patient's anxiety and fear of anesthesia: effect of gender, age, education, and previous experience of anesthesia. A survey of 400 patients," Journal of Anesthesia, vol. 27, no. 1, pp. 104-108, 2013.

[48] J. K. Kiecolt-Glaser, G. G. Page, P. T. Marucha, R. C. MacCallum, and R. Glaser, "Psychological influences on surgical recovery: perspectives from psychoneuroimmunology," American Psychologist, vol. 53, no. 11, pp. 1209-1218, 1998.

[49] P. B. Jacobsen and R. W. Butler, "Relation of cognitive coping and catastrophizing to acute pain and analgesic use following breast cancer surgery," Journal of Behavioral Medicine, vol. 19, no. 1, pp. 17-29, 1996.

[50] J. Katz, E. L. Poleshuck, C. H. Andrus et al., "Risk factors for acute pain and its persistence following breast cancer surgery," Pain, vol. 119, no. 1-3, pp. 16-25, 2005.

[51] M. R. Munafo and J. Stevenson, "Anxiety and surgical recovery: reinterpreting the literature," Journal of Psychosomatic Research, vol. 51, no. 4, pp. 589-596, 2001.

[52] J. Bruce, A. J. Thornton, N. W. Scott et al., "Chronic preoperative pain and psychological robustness predict acute postoperative pain outcomes after surgery for breast cancer," British Journal of Cancer, vol. 107, no. 6, pp. 937-946, 2012.

[53] J. Bruce, A. J. Thornton, R. Powell et al., "Psychological, surgical, and sociodemographic predictors of pain outcomes after breast cancer surgery: A Population-Based Cohort Study," Pain, vol. 155, no. 2, pp. 232-243, 2014.

[54] J. B. Schnur, I. Kafer, C. Marcus, and G. H. Montgomery, "Hypnosis to manage distress related to medical procedures: a meta-analysis," Contemporary Hypnosis, vol. 25, no. 3-4, pp. 114$128,2008$.

[55] J. B. Schnur, D. H. Bovbjerg, D. David et al., "Hypnosis decreases presurgical distress in excisional breast biopsy patients," Anesthesia and Analgesia, vol. 106, no. 2, pp. 440-444, 2008.

[56] G. H. Montgomery, D. H. Bovbjerg, J. B. Schnur et al., "A randomized clinical trial of a brief hypnosis intervention to control side effects in breast surgery patients," Journal of the National Cancer Institute, vol. 99, no. 17, pp. 1304-1312, 2007.

[57] E. V. Lang, K. S. Berbaum, S. Faintuch et al., "Adjunctive self-hypnotic relaxation for outpatient medical procedures: a prospective randomized trial with women undergoing large core breast biopsy," Pain, vol. 126, no. 1-3, pp. 155-164, 2006.

[58] B. Enqvist, C. Björklund, M. Engman, and J. Jakobsson, "Preoperative hypnosis reduces postoperative vomiting after surgery of the breasts. A prospective, randomized and blinded study," Acta Anaesthesiologica Scandinavica, vol. 41, no. 8, pp. 10281032, 1997.

[59] P. Forget and M. De Kock, "Could anaesthesia, analgesia and sympathetic modulation affect neoplasic recurrence after surgery? A systematic review centred over the modulation of natural killer cells activity," Annales Francaises d'Anesthesie et de Reanimation, vol. 28, no. 9, pp. 751-768, 2009.

[60] E. Neeman and S. Ben-Eliyahu, "Surgery and stress promote cancer metastasis: new outlooks on perioperative mediating mechanisms and immune involvement," Brain, Behavior, and Immunity, vol. 30, pp. S32-S40, 2013.

[61] S. Ben-Eliyahu, G. G. Page, and S. J. Schleifer, "Stress, NK cells, and cancer: still a promissory note," Brain, Behavior, and Immunity, vol. 21, no. 7, pp. 881-887, 2007.

[62] S. Ben-Eliyahu, G. Shakhar, G. G. Page, V. Stefanski, and K. Shakhar, "Suppression of NK cell activity and of resistance to metastasis by stress: a role for adrenal catecholamines and $\beta$ adrenoceptors," NeuroImmunoModulation, vol. 8, no. 3, pp. 154$164,2000$.

[63] S. Inbar, E. Neeman, R. Avraham, M. Benish, E. Rosenne, and S. Ben-Eliyahu, "Do stress responses promote leukemia progression? an animal study suggesting a role for epinephrine and prostaglandin-e2 through reduced nk activity," PLOS ONE, vol. 6, no. 4, Article ID e19246, 2011.

[64] R. Melamed, S. Bar-Yosef, G. Shakhar, K. Shakhar, and S. Ben-Eliyahu, "Suppression of natural killer cell activity and promotion of tumor metastasis by ketamine, thiopental, and halothane, but not by propofol: mediating mechanisms and prophylactic measures," Anesthesia and Analgesia, vol. 97, no. 5, pp. 1331-1339, 2003.

[65] P. Forget, C. Bentin, J.-P. Machiels, M. Berliere, P. G. Coulie, and M. De Kock, "Intraoperative use of ketorolac or diclofenac is associated with improved disease-free survival and overall survival in conservative breast cancer surgery," British Journal of Anaesthesia, vol. 113, supplement 1, pp. i82-i87, 2014.

[66] Á. Heaney and D. J. Buggy, "Can anaesthetic and analgesic techniques affect cancer recurrence or metastasis?" British Journal of Anaesthesia, vol. 109, no. 1, pp. i17-i28, 2012.

[67] P. Forget, J. Vandenhende, M. Berlière et al., "Do intraoperative analgesics influence breast cancer recurrence after mastectomy? A retrospective analysis," Anesthesia and Analgesia, vol. 110, no. 6, pp. 1630-1635, 2010.

[68] G. Shakhar and S. Ben-Eliyahu, "Potential prophylactic measures against postoperative immunosuppression: could they reduce recurrence rates in oncological patients?" Annals of Surgical Oncology, vol. 10, no. 8, pp. 972-992, 2003.

[69] H. Beloeil and K. Nouette-Gaulain, "The perioperative period in cancer surgery: a critical moment! Is there a role for regional anesthesia in preventing cancer recurrence?" Annales Francaises d'Anesthesie et de Reanimation, vol. 31, no. 6, pp. 528536, 2012.

[70] C. A. Deegan, D. Murray, P. Doran, P. Ecimovic, D. C. Moriarty, and D. J. Buggy, "Effect of anaesthetic technique on oestrogen receptor-negative breast cancer cell function in vitro," British Journal of Anaesthesia, vol. 103, no. 5, pp. 685-690, 2009.

[71] D. I. Sessler, "Does regional analgesia reduce the risk of cancer recurrence? A hypothesis," European Journal of Cancer Prevention, vol. 17, no. 3, pp. 269-272, 2008.

[72] S. Bar-Yosef, R. Melamed, G. G. Page, G. Shakhar, K. Shakhar, and S. Ben-Eliyahu, "Attenuation of the tumor-promoting effect of surgery by spinal blockade in rats," Anesthesiology, vol. 94, no. 6, pp. 1066-1073, 2001.

[73] A. K. Exadaktylos, D. J. Buggy, D. C. Moriarty, E. Mascha, and D. I. Sessler, "Can anesthetic technique for primary breast cancer surgery affect recurrence or metastasis?" Anesthesiology, vol. 105, no. 4, pp. 660-664, 2006.

[74] P. Lirk, R. Berger, M. W. Hollmann, and H. Fiegl, "Lidocaine time- and dose-dependently demethylates deoxyribonucleic acid in breast cancer cell lines in vitro," British Journal of Anaesthesia, vol. 109, no. 2, pp. 200-207, 2012. 
[75] E. Lucchinetti, A. E. Awad, M. Rahman et al., "Antiproliferative effects of local anesthetics on mesenchymal stem cells: potential implications for tumor spreading and wound healing," Anesthesiology, vol. 116, no. 4, pp. 841-856, 2012.

[76] C. Jose, N. Bellance, E. H. Chatelain, G. Benard, K. NouetteGaulain, and R. Rossignol, "Antiproliferative activity of levobupivacaine and aminoimidazole carboxamide ribonucleotide on human cancer cells of variable bioenergetic profile," Mitochondrion, vol. 12, no. 1, pp. 100-109, 2012.

[77] G. E. Miller and S. Cohen, "Psychological interventions and the immune system: a meta-analytic review and critique," Health Psychology, vol. 20, no. 1, pp. 47-63, 2001.

[78] J. Gruzelier, F. Smith, A. Nagy, and D. Henderson, "Cellular and humoral immunity, mood and exam stress: the influences of self-hypnosis and personality predictors," International Journal of Psychophysiology, vol. 42, no. 1, pp. 55-71, 2001.

[79] J. H. Gruzelier, "A review of the impact of hypnosis, relaxation, guided imagery and individual differences on aspects of immunity and health," Stress, vol. 5, no. 2, pp. 147-163, 2002.

[80] A. Naito, T. M. Laidlaw, D. C. Henderson, L. Farahani, P. Dwivedi, and J. H. Gruzelier, "The impact of self-hypnosis and Johrei on lymphocyte subpopulations at exam time: a controlled study," Brain Research Bulletin, vol. 62, no. 3, pp. 241-253, 2003.

[81] J. K. Kiecolt-Glaser, P. T. Marucha, C. Atkinson, and R. Glaser, "Hypnosis as a modulator of cellular immune dysregulation during acute stress," Journal of Consulting and Clinical Psychology, vol. 69, no. 4, pp. 674-682, 2001.

[82] K. D. Hudacek, "A review of the effects of hypnosis on the immune system in breast cancer patients: a brief communication," International Journal of Clinical and Experimental Hypnosis, vol. 55, no. 4, pp. 411-425, 2007.

[83] O. Eremin, M. B. Walker, E. Simpson et al., "Immunomodulatory effects of relaxation training and guided imagery in women with locally advanced breast cancer undergoing multimodality therapy: a randomised controlled trial," Breast, vol. 18, no. 1, pp. 17-25, 2009.

[84] J. S. Blake-Mortimer, S. E. Sephton, R. W. Carlson, D. Stites, and D. Spiegel, "Cytotoxic T lymphocyte count and survival time in women with metastatic breast cancer," Breast Journal, vol. 10, no. 3, pp. 195-199, 2004.

[85] D. Spiegel, H. Kraemer, J. Bloom, and E. Gottheil, "Effect of psychosocial treatment on survival of patients with metastatic breast cancer," The Lancet, vol. 334, no. 8668, pp. 888-891, 1989.

[86] D. Spiegel, L. D. Butler, J. Giese-Davis et al., "Effects of supportive-expressive group therapy on survival of patients with metastatic breast cancer: a randomized prospective trial," Cancer, vol. 110, no. 5, pp. 1130-1138, 2007.

[87] E. Damaser, W. G. Whitehouse, M. T. Orne, E. C. Orne, and D. F. Dinges, "Behavioral persistence in carrying out a posthypnotic suggestion beyond the hypnotic context: a consideration of the role of perceived demand characteristics," International Journal of Clinical and Experimental Hypnosis, vol. 58, no. 1, pp. 1-20, 2010.

[88] S. W. G. Derbyshire, M. G. Whalley, and D. A. Oakley, "Fibromyalgia pain and its modulation by hypnotic and nonhypnotic suggestion: an fMRI analysis," European Journal of Pain, vol. 13, no. 5, pp. 542-550, 2009.

[89] M. H. Antoni, S. K. Lutgendorf, S. W. Cole et al., "The influence of bio-behavioural factors on tumour biology: pathways and mechanisms," Nature Reviews Cancer, vol. 6, no. 3, pp. 240-248, 2006.
[90] E. S. Costanzo, A. K. Sood, and S. K. Lutgendorf, "Biobehavioral influences on cancer progression," Immunology and Allergy Clinics of North America, vol. 31, no. 1, pp. 109-132, 2011.

[91] G. G. Page, W. P. Blakely, and S. Ben-Eliyahu, "Evidence that postoperative pain is a mediator of the tumor-promoting effects of surgery in rats," Pain, vol. 90, no. 1-2, pp. 191-199, 2001.

[92] T. Tasmuth, K. von Smitten, and E. Kalso, "Pain and other symptoms during the first year after radical and conservative surgery for breast cancer," British Journal of Cancer, vol. 74, no. 12, pp. 2024-2031, 1996.

[93] F. Wang, X. Shen, S. Xu et al., "Negative words on surgical wards result in therapeutic failure of patient-controlled analgesia and further release of cortisol after abdominal surgeries," Minerva Anestesiologica, vol. 74, no. 7-8, pp. 353-365, 2008.

[94] C. Ginandes, P. Brooks, W. Sando, C. Jones, and J. Aker, "Can medical hypnosis accelerate post-surgical wound healing? Results of a clinical trial," American Journal of Clinical Hypnosis, vol. 45, no. 4, pp. 333-351, 2003.

[95] M. Berlière, S. Lamerant, P. Piette et al., "Potential benefits of hypnosis sedation on different modalities of breast cancer treatment," in Proceedings of the San Antonio Breast Cancer Symposium, Poster Session 2, P2-18-03, December 2014.

[96] M. Meurisse, E. Hamoir, T. Defechereux et al., "Bilateral neck exploration under hypnosedation: a new standard of care in primary hyperparathyroidism?" Annals of Surgery, vol. 229, no. 3, pp. 401-408, 1999.

[97] D. A. Rapkin, M. Straubing, and J. C. Holroyd, "Guided imagery, hypnosis and recovery from head and neck cancer surgery: an exploratory study," International Journal of Clinical and Experimental Hypnosis, vol. 39, no. 4, pp. 215-226, 1991.

[98] E. V. Lang and M. P. Rosen, "Cost analysis of adjunct hypnosis with sedation during outpatient interventional radiologic procedures," Radiology, vol. 222, no. 2, pp. 375-382, 2002.

[99] K. I. Block, "Could integrative cancer treatment be costsaving and resuscitate a submerged medical system?" Integrative Cancer Therapies, vol. 8, no. 3, pp. 205-207, 2009.

[100] G. H. Montgomery, D. David, G. Winkel, J. H. Silverstein, and D. H. Bovbjerg, "The effectiveness of adjunctive hypnosis with surgical patients: a meta-analysis," Anesthesia and Analgesia, vol. 94, no. 6, pp. 1639-1645, 2002.

[101] H. Cramer, R. Lauche, A. Paul, J. Langhorst, S. Kümmel, and G. J. Dobos, "Hypnosis in breast cancer care: a systematic review of randomized controlled trials," Integrative Cancer Therapies, vol. 14, no. 1, pp. 5-15, 2015. 


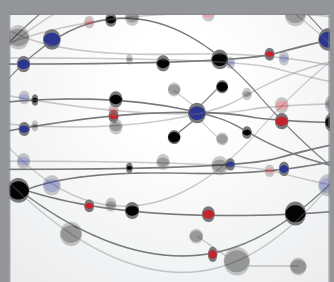

The Scientific World Journal
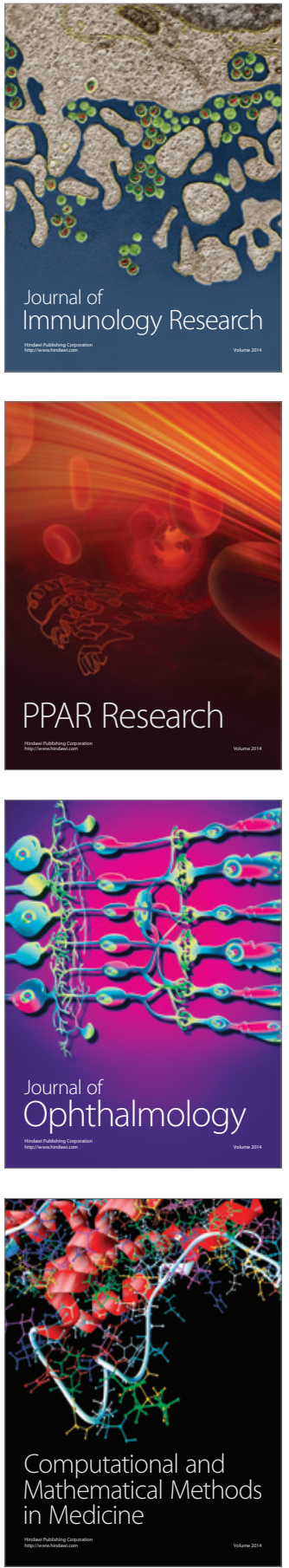

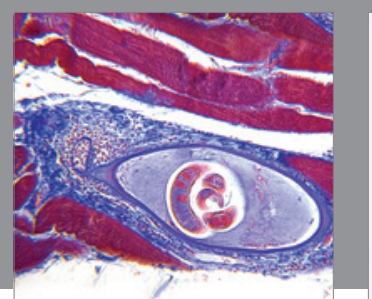

Gastroenterology Research and Practice

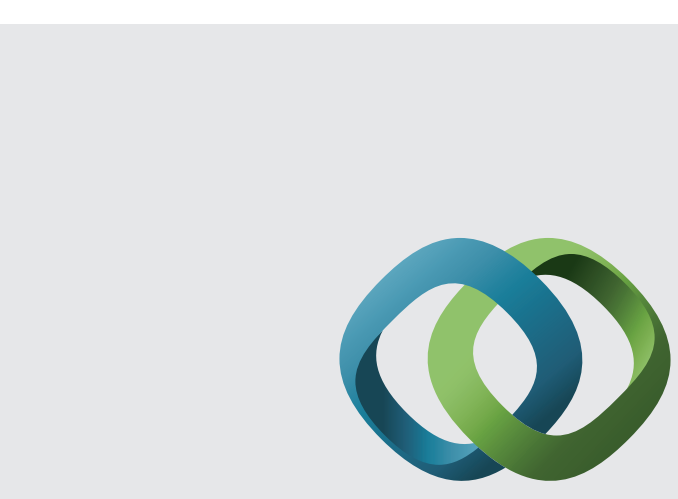

\section{Hindawi}

Submit your manuscripts at

http://www.hindawi.com
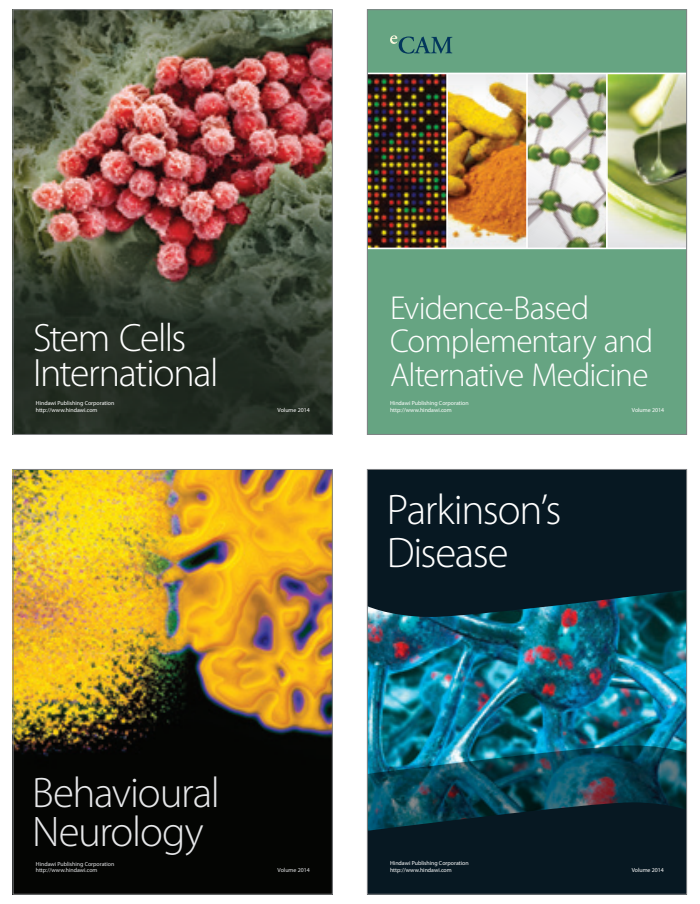
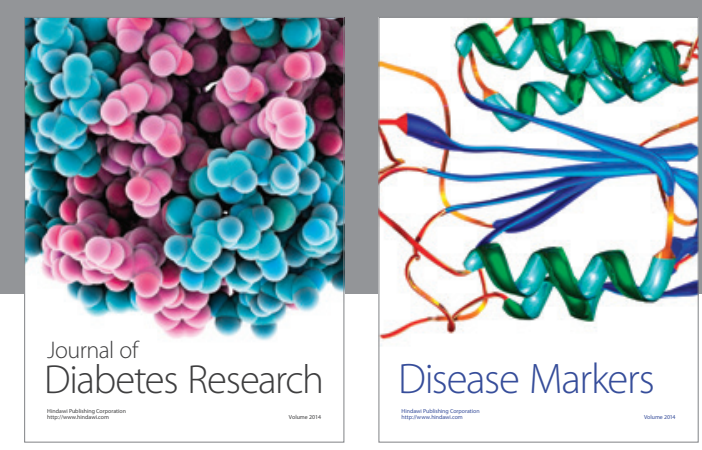

Disease Markers
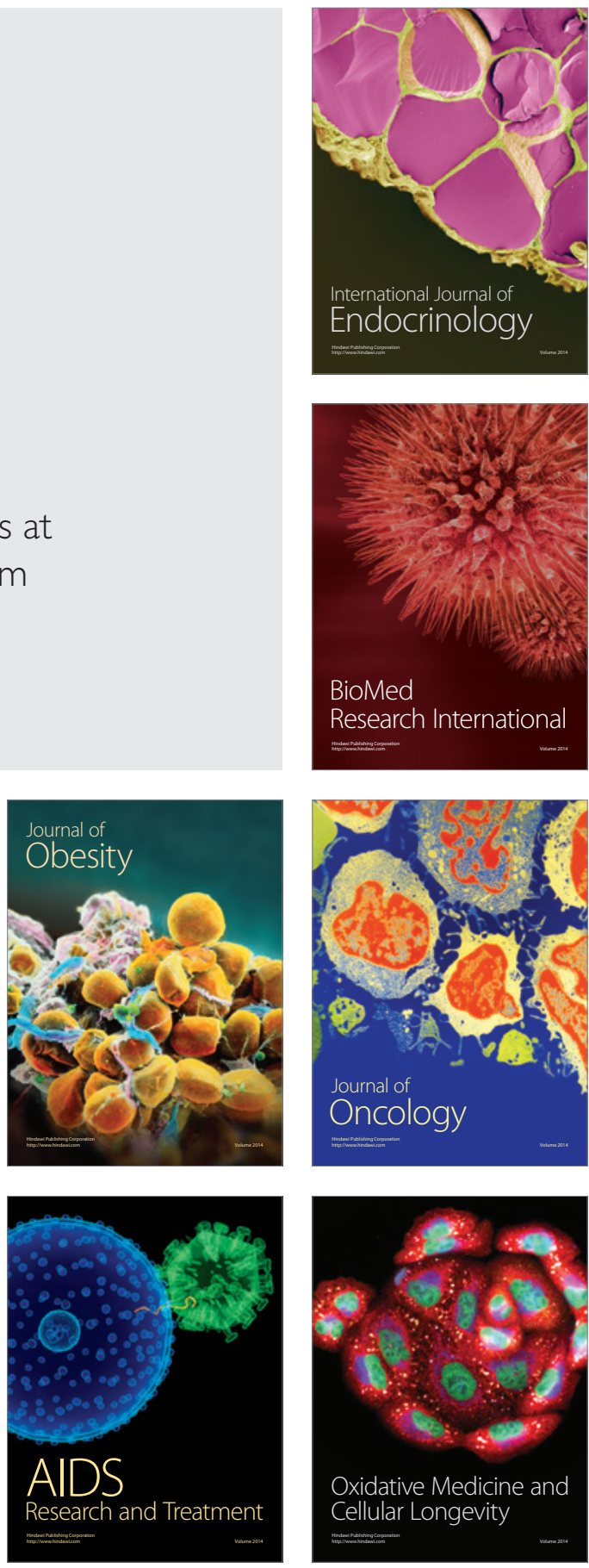